\title{
Cortical and Subcortical Gray Matter Abnormalities in Schizophrenia Determined Through Structural Magnetic Resonance Imaging With Optimized Volumetric Voxel-Based Morphometry
}

Hema Ananth, M.B., B.S., M.R.C.Psych.

Ioana Popescu, M.B., B.S., M.R.C.Psych.

Hugo D. Critchley, M.B., Ch.B., D.Phil., M.R.C.Psych.

Catriona D. Good, M.B., Ch.B., F.Rad., F.R.C.R.

Richard S.J. Frackowiak, M.D., D.SC., F.R.C.P.

Raymond J. Dolan, M.D., F.Med.Sci., F.R.C.Psych.
Objective: Structural neuroimaging studies have suggested an association between schizophrenia and abnormalities in brain morphology such as ventricular enlargement and differences in gray matter distribution. Less consistently reported are findings of regional abnormalities such as selective differences in thalamic volume. The authors applied an unbiased technique to test for differences in cerebral morphometry between patients with schizophrenia and matched comparison subjects.

Method: $\mathrm{T}_{1}$-weighted images from 20 schizophrenic patients and matched comparison subjects were processed by using optimized automated voxel-based morphometry within multiple linear regression analyses.

Results: Global differences in gray matter volume were seen between the schizophrenic and comparison subjects, with selective regional gray matter differences noted in the mediodorsal thalamus and across cortical regions, including the ventral and medial prefrontal cortices. Within the schizophrenic subjects, a relationship was observed between gray matter volume loss in the medial prefrontal cortex and a positive family history of schizophrenia. There was no significant difference between patients and comparison subjects in rates of proportional gray matter reduction with age.

Conclusions: These observations confirm an association between thalamocortical morphometric abnormalities and schizophrenia, consistent with theoretical models of primary pathoetiological dysfunction in filtering, integration, and information transfer processes in patients with schizophrenia.

(Am J Psychiatry 2002; 159:1497-1505)

S ized in acute phases by delusions, hallucinations, and disordered thinking and chronically by apathy, flat affect, and social withdrawal. The course is chronic in a high proportion of cases, although the underlying pathophysiology is unknown. Early descriptions of schizophrenia as "dementia praecox" (1) argued for an organic degenerative basis to the disorder. However, despite a worldwide prevalence of $1 \%$ and annual service provision costs within the United Kingdom estimated at 2.6 billion pounds (2), the neuropathological basis of schizophrenia has remained elusive. Negative cognitive symptoms characterize the neuropsychological profiles of many patients with schizophrenia. However, many formulations of the "schizophrenic mind" suggest a primary selective dysfunction of brain processes involved in filtering and gating information (3).

Histological evidence for a neurodegenerative process underlying schizophrenia is limited by a paucity of postmortem studies and methodological inconsistencies with techniques. High-resolution in vivo brain imaging has given impetus to understanding the neurobiology of schizophrenia, including the description of changes in brain morphology that may provide insights into etiological mechanisms. Among the most consistent neuroimaging findings in schizophrenia are greater cerebroventricular size and cerebral gray matter deficits (4-8), which suggests the presence of diffuse brain pathology. Observations of localized morphometric abnormalities in patients with schizophrenia have been less consistent across studies. In a meta-analysis of 58 morphometric studies of schizophrenia (with the majority having employed manual tracing of regions of interest), differences in medial temporal lobe structure volumes were the most frequent observations (8). Morphometric abnormalities in the thalamus have also been reported (9-11) and may reflect changes maximally localized within the mediodorsal thalamic nucleus (12). This finding is of note, since thalamic dysfunction, potentially leading to impaired sensory filtering and gating mechanisms, has been proposed to underlie the psychological abnormalities that characterize schizophrenia (13-16).

Voxel-based morphometry provides an automated means of comparing structural features across scans and overcomes problems of intra- and interobserver bias and 
TABLE 1. Demographic and Clinical Characteristics of 20 Patients With Schizophrenia Who Underwent Structural Magnetic Resonance Imaging Optimized Through the Use of Volumetric Voxel-Based Morphometry

\begin{tabular}{|c|c|c|c|c|c|c|c|c|c|}
\hline Patient & Sex & $\begin{array}{c}\text { Age at Time of } \\
\text { Scan (years) }\end{array}$ & Handedness & $\begin{array}{l}\text { Duration of } \\
\text { Illness (years) }\end{array}$ & $\begin{array}{l}\text { Family History } \\
\text { of Psychosis }\end{array}$ & Education ${ }^{b}$ & $\begin{array}{l}\text { Social } \\
\text { Class }^{c}\end{array}$ & Symptoms $^{d}$ & $\begin{array}{c}\text { Antipsychotic } \\
\text { Treatment }\end{array}$ \\
\hline 1 & $M$ & 55 & Right & 34 & Unknown & 0 & IV & $\mathrm{N} / \mathrm{P}$ & Olanzapine \\
\hline 2 & $M$ & 43 & Left & 18 & 0 & 0 & V & $\mathrm{N} / \mathrm{P}$ & Clozapine \\
\hline 3 & $\mathrm{~F}$ & 29 & Right & 8 & 0 & 2 & III & $\mathrm{N} / \mathrm{P}$ & Olanzapine \\
\hline 4 & $\mathrm{~F}$ & 34 & Right & 5 & 2 & 0 & IV & $\mathrm{N} / \mathrm{P}$ & Clozapine \\
\hline 5 & $\mathrm{~F}$ & 51 & Right & 22 & 2 & 1 & II & $\mathrm{N} / \mathrm{P}$ & Clozapine \\
\hline 6 & $\mathrm{~F}$ & 36 & Right & 19 & 2 & 1 & III & $\mathrm{P}$ & Clozapine \\
\hline 7 & $M$ & 36 & Right & 19 & 0 & 0 & V & $\mathrm{N} / \mathrm{P}$ & Clozapine \\
\hline 8 & $M$ & 38 & Right & 23 & 0 & 1 & II & $\mathrm{N} / \mathrm{P}$ & Clozapine \\
\hline 9 & $\mathrm{M}$ & 38 & Right & 19 & 1 & 0 & $\mathrm{~V}$ & $\mathrm{~N} / \mathrm{P}$ & Olanzapine \\
\hline 10 & $M$ & 24 & Right & 2 & 0 & 3 & IV & $\mathrm{N} / \mathrm{P}$ & Trifluoperazine \\
\hline 11 & $\mathrm{~F}$ & 27 & Right & 11 & 0 & 2 & IV & $\mathrm{P}$ & Trifluoperazine \\
\hline 12 & $\mathrm{~F}$ & 37 & Right & 11 & 0 & 1 & III & $\mathrm{P}$ & Clozapine \\
\hline 13 & $\mathrm{~F}$ & 31 & Right & 15 & 2 & 0 & III & $\mathrm{P}$ & Clozapine \\
\hline 14 & $M$ & 31 & Right & 15 & 0 & 0 & II & $\mathrm{N} / \mathrm{P}$ & Olanzapine \\
\hline 15 & $\mathrm{~F}$ & 47 & Right & 16 & 0 & 0 & IV & $\mathrm{N} / \mathrm{P}$ & Clozapine \\
\hline 16 & $\mathrm{~F}$ & 37 & Right & 10 & 0 & 2 & II & $\mathrm{N} / \mathrm{P}$ & Risperidone \\
\hline 17 & $\mathrm{~F}$ & 31 & Left & 4 & 2 & 1 & IV & $\mathrm{P}$ & Flupentixol \\
\hline 18 & $M$ & 58 & Right & 41 & 0 & 0 & III & $\mathrm{N}$ & Olanzapine \\
\hline 19 & $\mathrm{M}$ & 29 & Right & 5 & 0 & 1 & V & $\mathrm{N} / \mathrm{P}$ & Pipothiazine \\
\hline 20 & $\mathrm{M}$ & 47 & Right & 20 & 2 & 1 & IV & $\mathrm{P}$ & Fluphenazine \\
\hline
\end{tabular}

a $0=$ no family history, $1=$ psychosis in second-degree relative, $2=$ psychosis in first-degree relative.

${ }^{\mathrm{b}} 0=$ no academic qualifications, $1=$ schooling until 16 years of age, $2=$ schooling until 18 years of age, $3=$ degree equivalent.

' Determined according to the Hollingshead Index on the basis of father's occupation: I=highest, $V=$ lowest.

${ }^{d}$ Clinical description of subject's predominant presentation: $\mathrm{N}=$ negative symptoms, $\mathrm{P}=$ positive symptoms, $\mathrm{N} / \mathrm{P}=$ negative and positive symptoms equally severe.

sensitivity in assessing differences in cerebral morphology between groups of subjects (17-19). The first application of this technique to whole-brain magnetic resonance imaging (MRI) scans of patients with schizophrenia reported gray matter deficits in the insula and prefrontal and lateral temporal cortices (7). Similar methods have also been used to relate gray matter deficits in the medial prefrontal cortex, insula, and superior temporal cortex to severity of schizophrenic symptoms. Abnormalities in the thalamus, posterior cingulate, and basal ganglia, with ventricular enlargement, have been associated with childhood-onset schizophrenia (20). Voxel-based morphometry has also been applied to analysis of scans obtained by using magnetic transfer imaging, an MRI technique sensitive to subtle changes in regional macromolecular integrity (21). Frontotemporal abnormalities were noted in schizophrenic patients, and severity of negative schizophrenic symptoms reflected abnormal integrity of the medial prefrontal cortex. These and similar voxel-based morphometry studies point to a combination of diffuse gray matter volume deficits and more localized frontotemporal changes, perhaps selectively involving thalamocortical circuitry.

Recent methodological developments have optimized voxel-based morphometry techniques $(18,19)$, improving sensitivity to morphometric differences and control for macroscopic features. In standard voxel-based morphometry, erroneous missegmented voxels may appear in segmented images because of systematic differences in skull size, shape, or thickness across study groups. These problems have been addressed in an optimization of the methodology by addition of further preprocessing steps to exclude nonbrain voxels before normalization and subsequent segmentation, including a fully automatic brain extraction technique, study-specific gray/white matter templates, and a modulation step that incorporates volume changes during normalization into the analysis. This modulation procedure allows assessment of specific changes in regional gray/white matter volume. In this study, these methods were applied to test the specific hypothesis that characteristic differences exist between schizophrenic subjects and healthy comparison subjects in global and regional brain morphology.

\section{Method}

\section{Subjects}

Twenty patients with an ICD-10-R diagnosis of schizophrenia were recruited from local psychiatric centers and gave written, fully informed consent to participate in a structural magnetic resonance imaging study approved by the local ethics committee. Comparison subjects were recruited from healthy volunteers who were matched closely with the patients on the basis of age (schizophrenic patients: mean $=37.8$ years $[\mathrm{SD}=9.5]$, comparison subjects: mean=38.6 years $[\mathrm{SD}=9.7])$, gender $(10$ men and 10 women in each group), social class, and ethnicity. Detailed demographic and clinical characteristics of the patients were obtained from medical notes and corroborated by clinical interview. Patients were also rated by their supervising psychiatrist regarding negative and positive symptoms. Independent structured symptom quantification (e.g., the Positive and Negative Syndrome Scale) was not available for all patients. As seen in Table 1, all patients had a history of treatment with antipsychotic medication (mean treatment duration was 15 years [SD=9]) and were stable at the time of scanning. No subject had a history of neurological or systemic illness, head injury, or excessive drug or alcohol misuse. For within-patient analyses of putative influences on brain morphometry and psychotic illness, educational achievement was rated on a 4-point scale: $0=$ no academic qualifications, $1=$ schooling until 16 years of 
FIGURE 1. Gray Matter, White Matter, and CSF Volumes in Patients With Schizophrenia and Matched Comparison Subjects and Images Depicting Locations of Uncorrected Gray Matter Differences

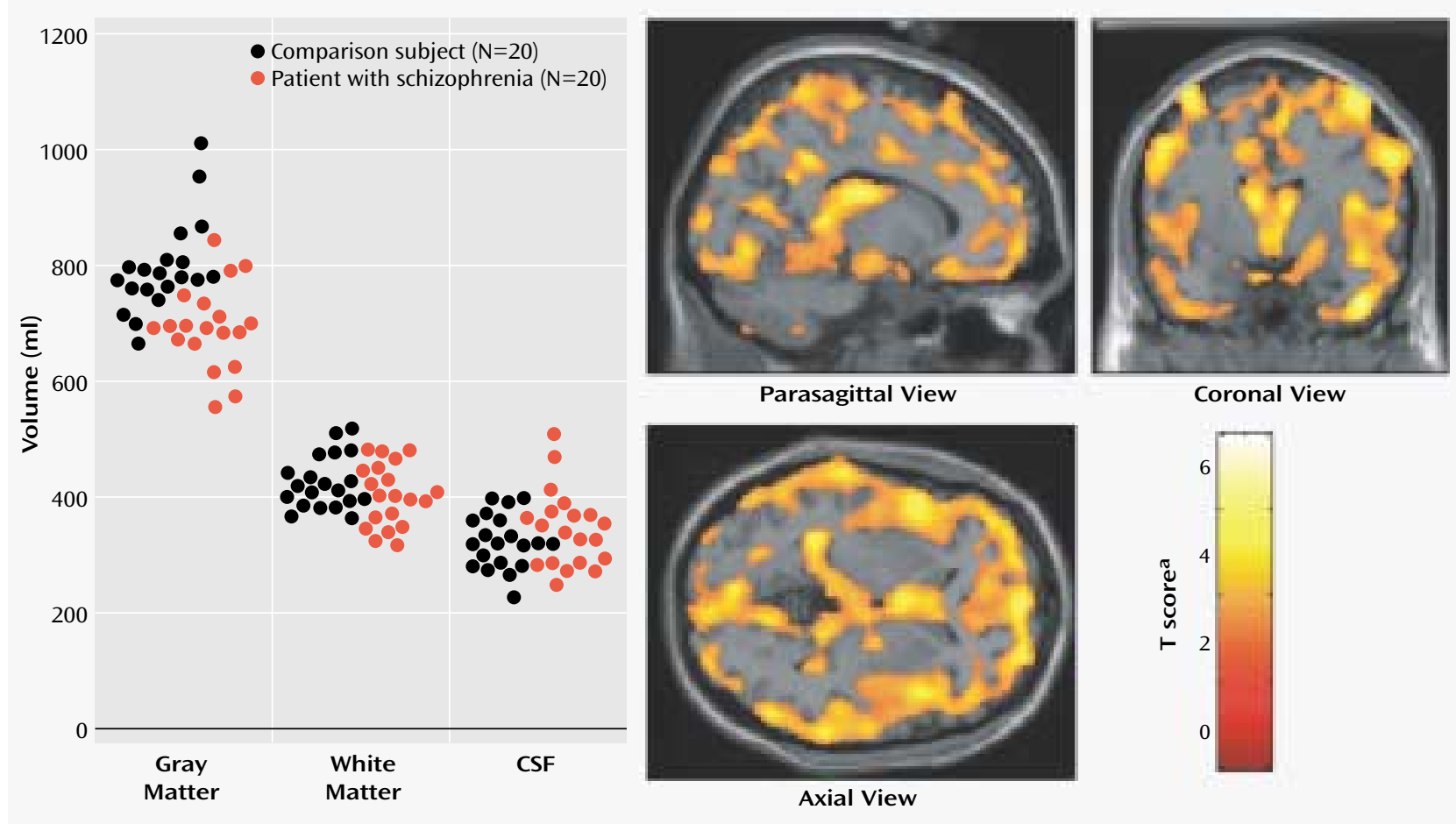

a Derived from multiple regression analyses of segmented gray matter images (with total intracranial volume, age, and gender as covariates) and plotted on sections of a normalized template brain. Significant morphological differences $(p<0.001)$ were uncorrected for multiple comparisons over the whole brain to illustrate the widespread distribution of gray matter differences.

age, $2=$ schooling until 18 years of age, and $3=$ attainment of a degree or equivalent. Family history of psychosis was scored as follows: $0=$ no family history, $1=$ psychosis in a second-degree relative, and $2=$ psychosis in a first-degree relative. Past substance abuse was scored clinically from 0 (no significant history) to 3 (past diagnosis of dependence syndrome, polysubstance abuse, or dual diagnosis). A score of 3 excluded the subject from the study.

\section{Imaging Data Acquisition}

Subjects were scanned on a 2-T Siemens Magnetom Vision scanner (Siemens Medical Solutions, Erlangen, Germany). A three-dimensional structural MRI scan was acquired for each subject by using a $\mathrm{T}_{1}$-weighted MPRAGE sequence ( $\mathrm{TR}=9.7 \mathrm{msec}$, $\mathrm{TE}=4 \mathrm{msec}, \mathrm{TI}=600 \mathrm{msec}$, number of excitations $=1$, flip angle $=12^{\circ}$, matrix size $=256 \times 192 \mathrm{~mm}$, and field of view $=256 \times 192 \mathrm{~mm}$, yield ing 120 sagittal slices with a thickness of $1.5 \mathrm{~mm}$ and in-plane resolution of $1 \mathrm{~mm} \times 1 \mathrm{~mm}$ ).

\section{Data Preprocessing for Voxel-Based Morphometry}

An optimized voxel-based morphometry protocol was followed for preprocessing and subsequent analysis of imaging data. This method, described previously in detail (17-19), was implemented within Matlab5.3 (MathWorks, Natick, Mass.) through Statistical Parametric Mapping (SPM 99, Wellcome Department of Imaging Neuroscience, London; available at http://www.fil.ion.ucl.ac.uk/ spm) $(22,23)$.

Preprocessing of structural data followed a number of defined stages. First, customized gray and white matter templates were created from an independent separate matched comparison group, imaged with identical methods on the same scanner. Each structural MRI was normalized to the standard statistical parametric mapping $\mathrm{T}_{1}$ template; segmented into CSF, gray matter, and white matter compartments; then smoothed (8-mm full width at half maximum isotropic Gaussian kernel) and averaged to create gray and white matter templates in stereotactic space. Next, for the study group MRIs, an automated brain extraction procedure that incorporated a segmentation step was used to remove nonbrain tissue $(18,19)$. Extracted gray and white matter images were normalized to the gray and white matter templates. Spatial normalization used residual sum of squared differences as the matching criterion and included affine transformations and linear combination of smooth basis functions modelling global nonlinear shape differences $(17,24)$. The normalization parameters were then reapplied to the original structural images to maximize optimal segmentation of fully normalized images, and these normalized images were resliced to a final voxel size of 1.5 $\mathrm{mm}^{3}$ and segmented into gray/white matter and CSF/non-CSF partitions. The statistical parametric mapping segmentation employs a mixture model cluster analysis (after correcting for nonuniformity in image intensity) to identify voxel intensities that match particular tissue types combined with a priori probabilistic knowledge of the spatial distribution of tissues (25). After a further automated brain extraction step, the partitioned images were modulated by the Jacobian determinants from spatial normalization to correct for volume changes introduced during the nonlinear spatial transformations. Analysis of modulated data tested for regional differences in absolute amount (volume) of gray/white matter, in contrast to analysis of unmodulated data (17). Finally, all normalized, segmented modulated images were smoothed with a 12-mm full width at half maximum isotropic Gaussian kernel, which conditioned the residuals to conform more closely to the Gaussian random field model underlying the statistical process used for adjusting $p$ values $(24,26)$. 
TABLE 2. Regional Differences in Gray and White Matter Volume Between 20 Patients With Schizophrenia and 20 Matched Comparison Subjects

\begin{tabular}{lrrrlll}
\hline & \multicolumn{3}{c}{ Coordinates of } & & \\
\cline { 2 - 4 } Peak Difference & & \\
\cline { 2 - 4 } Matter Type and Region & $\mathrm{x}$ & $\mathrm{y}$ & $\mathrm{z}$ & & Side & T Score \\
\hline Gray matter & & & & & \\
$\quad$ Mediodorsal thalamus & -8 & -15 & 17 & Left & 7.70 \\
Middle occipital gyrus & 45 & -74 & 18 & Right & 7.52 \\
Medial frontal pole & 2 & 63 & 14 & - & 7.32 \\
Premotor/motor cortex & 42 & -5 & 65 & Right & 7.04 \\
Inferior temporal gyrus & 66 & -35 & -6 & Right & 7.03 \\
Fusiform gyrus & -23 & -74 & -9 & Left & 6.92 \\
Peristriate visual cortex & -6 & -75 & 18 & Left & 6.75 \\
Postcentral gyrus & 47 & -20 & 68 & Right & 6.68 \\
Superior frontal gyrus & 23 & 38 & 53 & Right & 6.62 \\
Inferior parietal lobule & 51 & -69 & 38 & Right & 6.61 \\
Inferior frontal gyrus & -45 & 15 & 36 & Left & 6.61 \\
Precentral gyrus & -39 & -5 & 68 & Left & 6.61 \\
Orbitofrontal cortex & 30 & 33 & -9 & Right & 6.50 \\
White matter: lateral optic & & & & & \\
radiation & -32 & -83 & 8 & Left & 5.77 \\
\hline
\end{tabular}

${ }^{a}$ All scores significant $(p<0.05)$ after family-wise error correction for multiple comparisons over the whole brain.

\section{Statistical Analysis}

Global measures of regional gray matter, white matter, and CSF volumes were calculated from the nonnormalized segmented images to test for group differences in overall tissue compartment volumes. Regional differences were analyzed by using multiple regression analyses within the framework of the general linear model in the statistical parametric mapping program $(22-24,27)$. Separate analytic design matrices were constructed to test for regional differences in gray and white matter between schizophrenic patients and comparison subjects. Age, gender, and total intracranial tissue volume (derived from the sum of the global measures of compartmental volumes) were entered as regressors (confounding covariates) in addition to the two regressors representing individual patients and comparison subjects. Further design matrices were used to test for morphometric changes within the schizophrenic patient group, correlating with putative influences on psychosis, with regressors entered for age at illness onset, handedness, level of educational achievement, family history of psychosis, past substance abuse, age, and gender.

Statistical parametric maps were constructed to test for morphological differences between schizophrenic patients and comparison subjects and for correlations between contextual variables within the schizophrenic group. The distribution of morphological differences across the whole brain was assessed initially on a voxel-by-voxel basis; a threshold of $\mathrm{p}<0.001$ was used, uncorrected for multiple comparisons. Significance corrections for multiple comparisons over the whole brain $(769,568$ voxels) were implemented by using family-wise error correction (akin to Bonferroni correction) (27). Inferences are centered on differences that achieved significance at $\mathrm{p}<0.05$, after family-wise error correction for multiple comparisons over the whole brain.

\section{Results}

\section{Global Differences}

In tests for global differences in absolute volume for gray matter, white matter, and CSF, we observed no significant difference between the schizophrenic patients and comparison subjects in a measure of total intracranial vol- ume, the sum of the global measures of the three tissue types obtained before normalization $(\mathrm{F}=0.05, \mathrm{df}=38, \mathrm{p}=$ 0.80 ). However, significant differences in cerebral gray matter were seen between the patients with schizophrenia (absolute volume mean $=713 \mathrm{ml}, \mathrm{SD}=77$ ) and the comparison subjects (mean=810 $\mathrm{ml}, \mathrm{SD}=81)(\mathrm{F}=15.4, \mathrm{df}=1,38$, $\mathrm{p}<0.01)$. There were no significant differences between schizophrenia patients and comparison subjects in overall white matter (mean=415 $\mathrm{ml}[\mathrm{SD}=56]$ and $441 \mathrm{ml}$ [SD=51], respectively) or CSF volume (mean=331 $\mathrm{ml}[\mathrm{SD}=54]$ and $321 \mathrm{ml}$ [SD=45]) (Figure 1). In tests of group differences corrected for intracranial volume, schizophrenic patients had a significantly lower proportion of relative gray matter volume than did the comparison subjects $(48.9 \%$ versus $51.6 \%$, respectively; $\mathrm{t}=3.66, \mathrm{df}=38, \mathrm{p}<0.01$ ) and a significantly higher proportion of relative CSF volume $(23.6 \%$ versus $20.6 \%$; $\mathrm{t}=-3.38, \mathrm{df}=38, \mathrm{p}<0.01$ ). There were no between-group differences in proportion of white matter (schizophrenic patients: $27.5 \%$, comparison subjects: $27.7 \%)(\mathrm{t}=0.40, \mathrm{df}=38, \mathrm{p}>0.05)$.

\section{Regional Differences}

Local differences in cerebral morphology associated with schizophrenia were analyzed by using voxel-wide comparisons of segmented gray matter, white matter, and CSF images, with subject age, gender, and total intracranial volume as confounding covariates. At a low threshold (i.e., uncorrected for multiple comparisons), a widespread distribution of significant gray matter differences $(\mathrm{p}<0.001)$ was observed in cortical and subcortical regions between the schizophrenic patients and the comparison subjects (Figure 1). Differences in many brain areas remained significant after a stringent family-wise error correction for multiple comparisons over the whole brain (Table 2), with the most robust difference in regional gray matter volume being observed in the mediodorsal thalamus, especially on the left (Figure 2). Regional differences maintaining significance after familywise error correction for multiple comparisons over the whole brain were observed in the occipitoparietal cortex; premotor, medial, and orbital prefrontal cortices; and the inferolateral temporal lobe (Table 2, Figure 3). There were no significant differences in any region (either corrected or uncorrected) in which gray matter volume in the schizophrenic patients was greater than that of the comparison subjects.

A significant difference in white matter volume was observed in a lateral optic radiation region in the occipital cortex $(\mathrm{p}<0.05$, after family-wise error correction for multiple comparisons over the whole brain) (Table 2). There were no significant differences in any region (either corrected or uncorrected) in which white matter volume in the schizophrenic patients was greater than that of the comparison subjects. 
FIGURE 2. Images Depicting Locations of Corrected Differences in Thalamic Gray Matter Between 20 Patients With Schizophrenia and 20 Matched Comparison Subjects and Individual Metrics for Coordinate With Largest Between-Group Difference $^{a}$
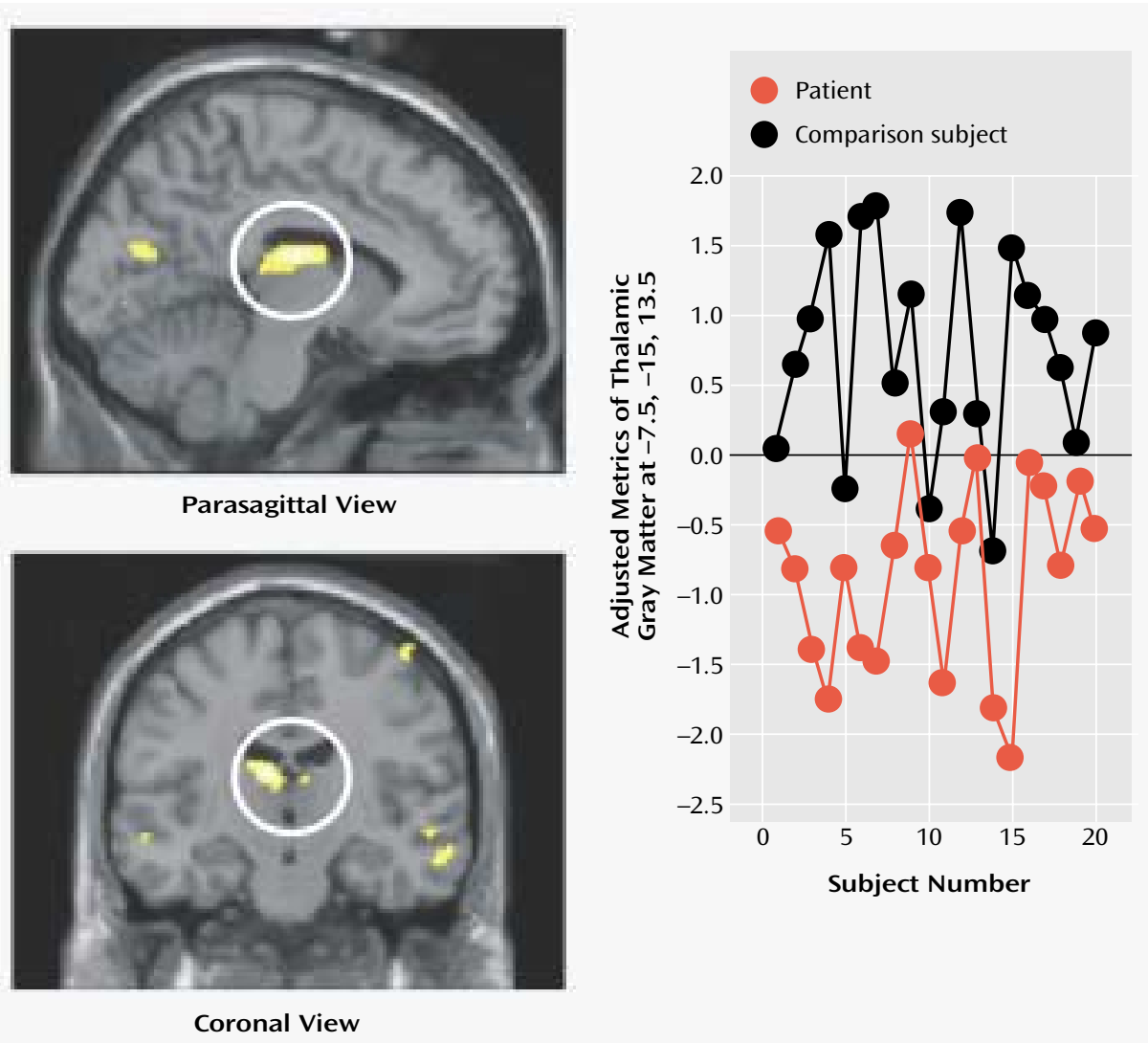

${ }^{a}$ Images on the left are sections of a normalized template brain on which the locations of significant differences in mediodorsal thalamic gray matter are plotted ( $p<0.05$, after family-wise error correction for multiple comparisons over the whole brain). The graph on the right illustrates subject-by-subject variation in relative mediodorsal thalamic gray matter at the coordinate of largest morphometric difference.

\section{Within-Patient Correlations}

To gain a clearer understanding of pathoetiological associations of morphometric abnormalities in patients with schizophrenia, we tested for correlations between gray matter volume deficits and variables that may influence psychosis (e.g., handedness, substance misuse, level of educational achievement) and more specific illnessrelated factors (age, family history of psychosis, and age at onset). A significant negative correlation was observed between total gray matter volume (as a proportion of intracranial volume) and age of schizophrenic patients ( $\mathrm{r}=-0.52$, $\mathrm{df}=18, \mathrm{p}<0.02$ ). However, the rate of relative gray matter depletion in schizophrenic patients was not significantly different than that observed in the comparison subjects, implying no acceleration of gray matter loss in schizophrenia (age-by-diagnosis interaction: $\mathrm{F}=1.01, \mathrm{df}=1,38, \mathrm{p}=0.32$ ). Greater educational achievement was associated with a relative "preservation" of (mediodorsal) thalamic gray matter in schizophrenic patients (Pearson $\mathrm{r}=0.48, \mathrm{df}=18, \mathrm{p}=$ 0.04 , two-tailed), and in regression analysis, ventromedial prefrontal gray matter showed a significant negative relationship with family history of schizophrenia (Figure 4).

\section{Discussion}

The present study used an optimized version of the voxel-based morphometry method to identify and characterize differences in brain structure associated with schizophrenia. Consistent with previous reports (4-8), we observed gray matter deficits and higher CSF volumes in schizophrenic patients. We also found regional differences in cortical and subcortical gray matter between schizophrenic patients and healthy comparison subjects, most significantly in the thalamus (especially the mediodorsal nucleus). These observations argue for thalamocortical dysfunction as a key component of pathoetiological mechanisms underlying symptoms and neuropsychological manifestations of schizophrenia.

The thalamus has previously been implicated in the pathoetiology of schizophrenia. Postmortem studies have reported neuronal loss in the maximal medial/mediodorsal thalamus of schizophrenia patients $(28,29)$, and previous in vivo imaging studies have reported thalamic abnormalities in patients with chronic schizophrenia (9-12, 30), untreated schizophrenia $(31,32)$, and childhood-onset 
FIGURE 3. Cortical and Subcortical Regions of Corrected Gray Matter Differences Between 20 Patients With Schizophrenia and 20 Matched Comparison Subjects ${ }^{a}$

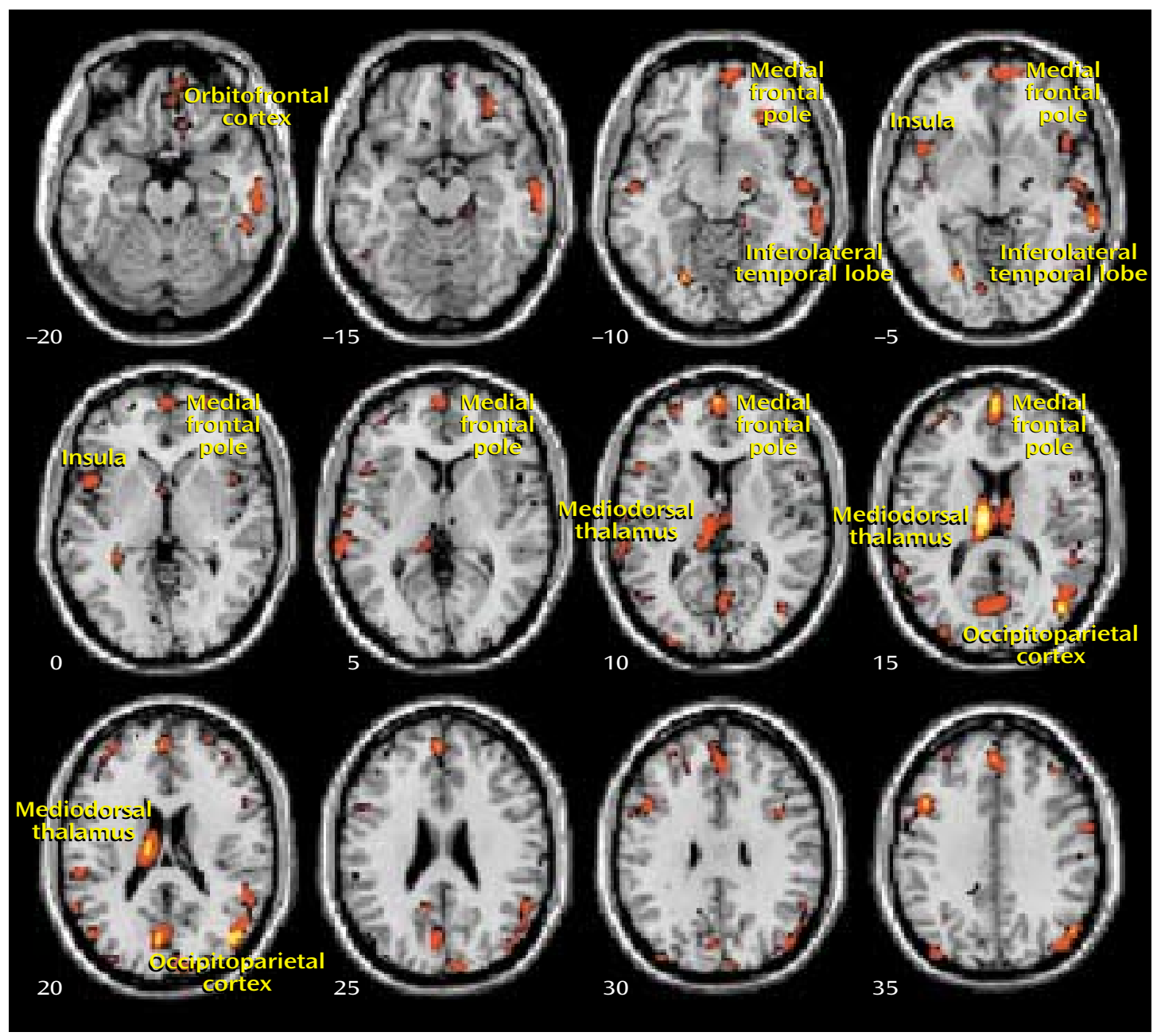

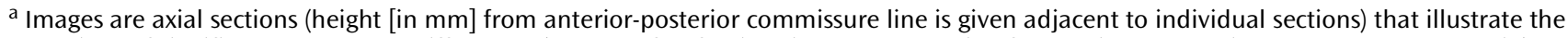
locations of significant gray matter differences ( $<<0.05$, after family-wise error correction for multiple comparisons over the whole brain).

schizophrenia (20) as well as relatives of schizophrenic patients (33) and schizotypal individuals (34). In the metaanalysis of Wright and colleagues (7), schizophrenia was associated with a mean $4 \%$ thalamic volume loss, with the proviso that only three studies contributed to this observed effect. Among studies that have failed to show thalamic volume differences between schizophrenic patients and healthy subjects (35-37), thalamic volume has been related to psychotic symptoms (35). Functional imaging studies involving patients with schizophrenia also report functional abnormalities involving the thalamus, including abnormal thalamic activity at rest (31), during auditory hallucinations (38), and during attentional and executive tasks $(39,40)$.

Our voxel-based morphometry findings add to the weight of evidence for structural abnormalities in the thalamus associated with schizophrenia. The conjunction of thalamic and distributed cortical gray matter depletion suggests that thalamocortical dysconnectivity may be cru- cial to the pathogenesis and symptoms of schizophrenia, consistent with specific theoretical models of cognitive integration and dysfunction in schizophrenia $(13,41)$. Anatomically, the thalamus is a crucial relay between sensory pathways and cortex and also between sensory cortices and association areas. A proposed role of the thalamus as a sensory filter has been elaborated in relation to schizophrenia within the notion of "cognitive dysmetria" $(13,15$, 42 ), wherein the fluid coordination of mental activity is disrupted. Neuroanatomically, corticocortical pathways involving both the thalamus and cerebellum have been suggested to coordinate sensory processing with mental activity and behavioral sequelae (15).

Dysfunction of coordinated regulation of sensory, motor, and cognitive processes may underlie abnormalities in sensory experience and attribution, motor coordination, and neuropsychological function spanning cognitive domains in schizophrenia $(3,43)$. Within this model, abnormal filtering and gating mechanisms may result in 
FIGURE 4. Images Depicting Locations of Corrected Differences in Prefrontal Gray Matter Between 20 Patients With Schizophrenia and 20 Matched Comparison Subjects and Relation of Individual Metrics to Family History of Psychosis for 19 Patients $^{\mathrm{a}}$

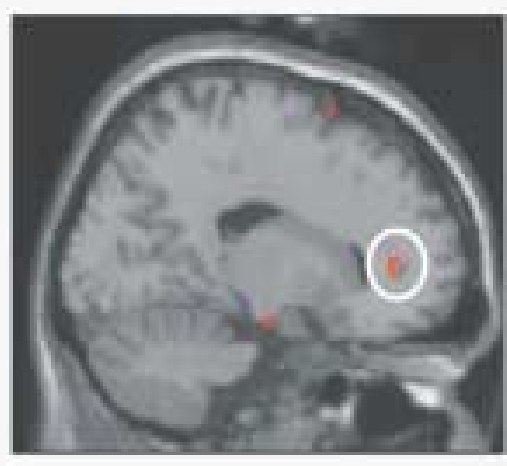

Parasagittal View

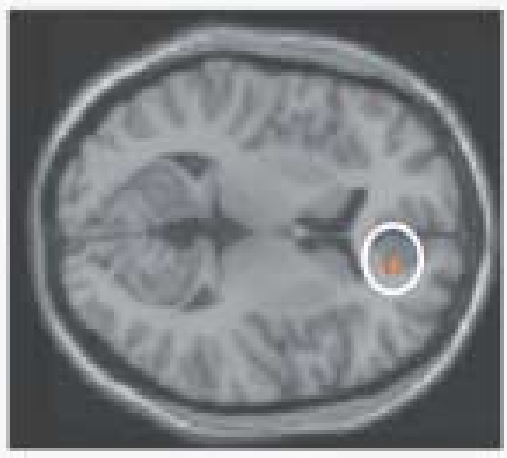

Axial View

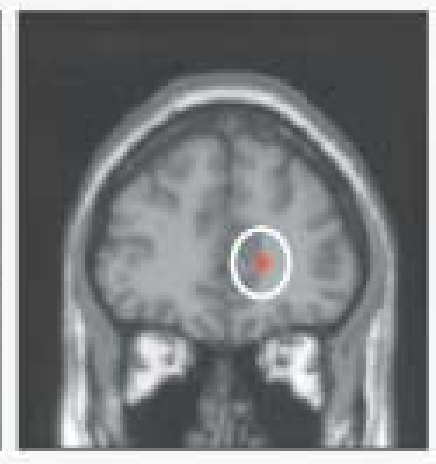

Coronal View

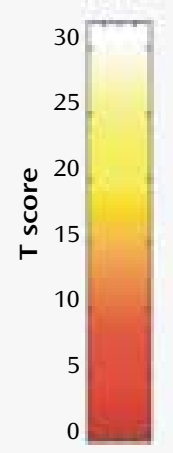

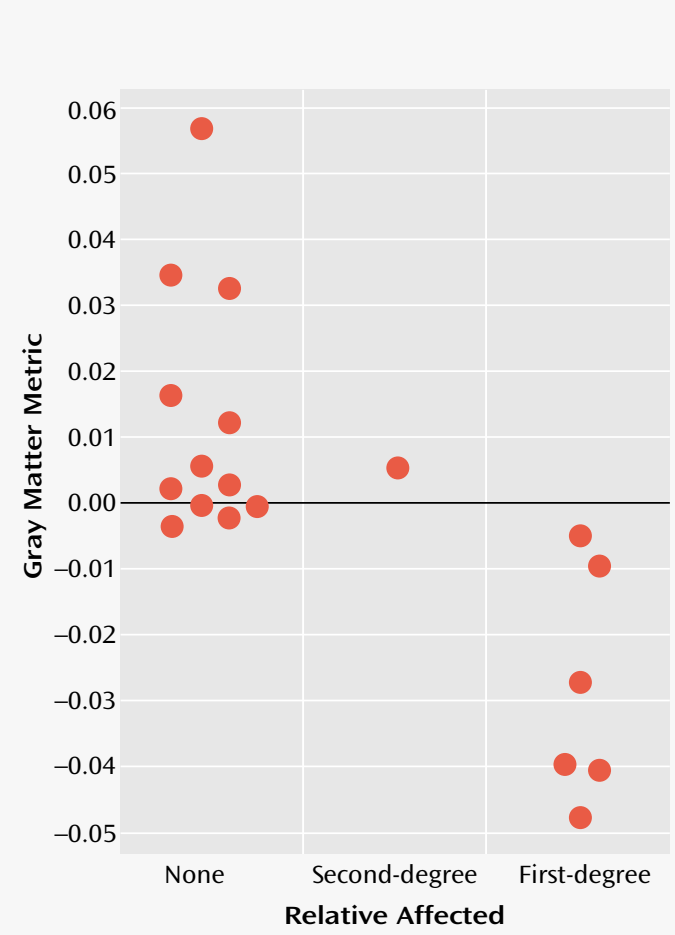

a Images on the left are sections of a normalized template brain on which are plotted locations of significant differences in medial prefrontal cortex gray matter $(\mathrm{p}<0.05$, after family-wise error correction for multiple comparisons over the whole brain). The graph on the right plots adjusted raw data from a regression analysis of ventromedial prefrontal gray matter and family history of psychosis in which a significant negative relationship was found $(r=-0.71, \mathrm{df}=17, \mathrm{p}=0.01)$.

disruption of synchronized signal processing (decreased signal to noise) within cortical association areas. The consequences of "mistimed information transfer" may account for hallucinations and delusions as misinterpretations of both external and internal percepts. Similarly, thought disorder may reflect uncoordinated language production, and negative dysexecutive symptoms may reflect deficits in associative processing of behavioral salience with sensory and mnemonic information. On this basis it has been argued that the integrity of thalamocortical connectivity, perhaps incorporating cerebellar mechanisms, is of primary pathoetiological importance in schizophrenia (15). Moreover, alterations in functional dynamics of thalamocortical networks may disrupt mechanisms supporting more general conscious integration, thereby contributing to schizophrenic symptoms (41). Our own findings of marked changes in thalamocortical architecture in schizophrenic patients add direct empirical evidence to support the theoretical proposal that functional abnormalities of this system underlie schizophrenia.

A key finding of our study was a demonstration of relationships between regional deficits in gray matter and clinical variables in schizophrenic patients. Although we observed a significant correlation between global reductions in gray matter and subjects' age, which suggests progressive, accelerated neuronal loss in schizophrenia, the rate of gray matter decline with age of schizophrenic patients was equivalent to that observed in healthy comparison subjects. Moreover, there were no significant correlations between morphological changes and either age at onset of illness or years of neuroleptic treatment. These observations argue against a progressive involutionary disorder associated with schizophrenia. It is therefore of clinical and theoretical interest whether chemotherapeutic interventions aimed at halting the progress of "dementia praecox" will have an impact on cognitive symptoms and age-related gray matter loss in some individuals with schizophrenia.

Thalamofrontal dysconnectivity may be particularly important in the pathoetiology of schizophrenia. Our observation that morphometric differences were most significant in the mediodorsal nucleus, which is reciprocally connected (and defines by its projection) to the prefrontal cortex, is noteworthy in that many of the cognitive deficits and symptom patterns manifested in schizophrenic patients are common to patients with prefrontal cortical le- 
sions (44-46). Moreover, the medial prefrontal cortex demonstrated the strongest morphometric association with family history of psychosis, implying that genetic factors underlying maturation of prefrontal cortex and its connections may increase vulnerability to schizophrenia. Also, a higher level of educational achievement was associated with relative preservation of mediodorsal thalamic gray matter in schizophrenic patients, perhaps indicating greater integrity of thalamofrontal circuitry supporting executive planning and verbal reasoning. This is clinically important, since good premorbid functioning, suggested by educational achievement, is associated with reduced negative symptoms and more positive outcome in schizophrenia (47).

A full understanding of the pathoetiology of schizophrenia remains an important goal, given the sociological and economic cost of maintaining services and therapeutic care for approximately $1 \%$ of individuals throughout the world. Recent technical advances, particularly in human genetics, molecular biology, and in vivo brain imaging, may lead to a more sophisticated understanding of biological mechanisms fundamental to mental health and disease. The present study used optimized voxel-based morphometry, which allows simultaneous, sensitive, and unbiased comparison of regional brain morphometry, thereby overcoming problems of region of interest hypothesis-driven analyses. Our evidence for thalamocortical gray matter depletion in schizophrenia, affecting distributed cortical regions, suggests a pathoetiological basis in re-entrant corticothalamic circuitry.

Received Nov. 15, 2001; revision received April 10, 2002; accepted April 11, 2002. From the Wellcome Department of Imaging Neuroscience, Institute of Neurology, University College London; and the National Hospital for Neurology and Neurosurgery, London. Address reprint requests to Dr. Dolan, Wellcome Department of Imaging Neuroscience, Institute of Neurology, University College London, 12 Queen Square, London WC1N 3BG, U.K.

Supported by the Wellcome Trust, a Wellcome Trust Programme Grant (Dr. Dolan), a Wellcome Trust Career Development Fellowship (Dr. Good), and a Wellcome Clinician Scientist Fellowship (Dr. Critchley).

\section{References}

1. Bleuler E: Dementia Praecox or the Group of Schizophrenias (1911). Translated by Zinkin J. New York, International Universities Press, 1950

2. Knapp M: Costs of schizophrenia. Br J Psychiatry 1997; 171: 509-518

3. Braff DL, Geyer MA: Sensorimotor gating and schizophrenia: human and animal model studies. Arch Gen Psychiatry 1990; 47:181-188

4. Weinberger DR, Torrey EF, Neophytides AN, Wyatt RJ: Structural abnormalities in the cerebral cortex of chronic schizophrenic patients. Arch Gen Psychiatry 1979; 36:935-939

5. Harvey I, Ron MA, Du Boulay G, Wicks D, Lewis SW, Murray RM: Reduction of cortical volume in schizophrenia on magnetic resonance imaging. Psychol Med 1993; 23:591-604

6. Lim KO, Tew W, Kushner M, Chow K, Matsumoto B, DeLisi LE: Cortical gray matter volume deficit in patients with first-episode schizophrenia. Am J Psychiatry 1996; 153:1548-1553
7. Wright IC, Ellison ZR, Sharma T, Friston KJ, Murray RM, McGuire PK: Mapping of gray matter changes in schizophrenia. Schizophr Res 1999; 35:1-14

8. Wright IC, Rabe-Hesketh S, Woodruff PWR, David AS, Murray RM, Bullmore ET: Meta-analysis of regional brain volumes in schizophrenia. Am J Psychiatry 2000; 157:16-25

9. Andreasen NC, Arndt S, Swayze V II, Cizadlo T, Flaum M, O'Leary D, Ehrhardt JC, Yuh WTC: Thalamic abnormalities in schizophrenia visualized through magnetic resonance image averaging. Science 1994; 266:294-298

10. Gilbert AR, Rosenberg DR, Harenski K, Spencer S, Sweeney JA, Keshavan MS: Thalamic volumes in patients with first-episode schizophrenia. Am J Psychiatry 2001; 158:618-624

11. Konick LC, Friedman L: Meta-analysis of thalamic size in schizophrenia. Biol Psychiatry 2001; 49:28-38

12. Byne W, Buchsbaum MS, Kemether E, Hazlett EA, Shinwari A, Mitropoulou V, Siever LJ: Magnetic resonance imaging of the thalamic mediodorsal nucleus and pulvinar in schizophrenia and schizotypal personality disorder. Arch Gen Psychiatry 2001; 58:133-140

13. Andreasen NC, O'Leary DS, Cizadlo T, Arndt S, Rezai K, Boles Ponto LL, Watkins GL, Hichwa RD: Schizophrenia and cognitive dysmetria: a positron-emission tomography study of dysfunctional prefrontal-thalamic-cerebellar circuitry. Proc Natl Acad Sci USA 1996; 93:9985-9990

14. Frith CD, Friston KJ, Herold S, Silbersweig D, Fletcher P, Cahill C, Dolan RJ, Frackowiak RS, Liddle PF: Regional brain activity in chronic schizophrenic patients during the performance of a verbal fluency task. Br J Psychiatry 1995; 167:343-349

15. Andreasen NC, Paradiso S, O'Leary DS: "Cognitive dysmetria" as an integrative theory of schizophrenia: a dysfunction in cortical-subcortical-cerebellar circuitry? Schizophr Bull 1998; 24: 203-218

16. Schultz SK, Andreasen NC: Schizophrenia. Lancet 1999; 353: 1425-1430

17. Ashburner J, Friston $\mathrm{KJ}$ : Voxel-based morphometry-the methods. Neuroimage 2000; 11:805-821

18. Good CD, Johnsrude IS, Ashburner J, Henson RN, Friston KJ, Frackowiak RS: A voxel-based morphometric study of ageing in 465 normal adult human brains. Neuroimage 2001; 14:21-36

19. Good CD, Johnsrude I, Ashburner J, Henson RN, Friston KJ, Frackowiak RS: Cerebral asymmetry and the effects of sex and handedness on brain structure: a voxel-based morphometric analysis of 465 normal adult human brains. Neuroimage 2001; 14:685-700

20. Sowell ER, Levitt J, Thompson PM, Holmes CJ, Blanton RE, Kornsand DS, Caplan R, McCracken J, Asarnow R, Toga AW: Brain abnormalities in early-onset schizophrenia spectrum disorder observed with statistical parametric mapping of structural magnetic resonance images. Am J Psychiatry 2000; 157:14751484

21. Foong J, Symms MR, Barker GJ, Maier M, Woermann FG, Miller $\mathrm{DH}$, Ron MA: Neuropathological abnormalities in schizophrenia: evidence from magnetization transfer imaging. Brain 2001; 124:882-892

22. Friston K, Ashburner J, Frith CD, Poline J-B, Heather JD, Frackowiak RSJ: Spatial registration and normalization of images. Hum Brain Mapp 1995; 2:165-189

23. Friston K, Holmes AP, Worsley K, Poline J-B, Frith CD, Frackowiak RSJ: Statistical parametric maps in functional imaging: a general linear approach. Hum Brain Mapp 1995; 2:189-210

24. Ashburner J, Neelin P, Collins DL, Evans A, Friston K: Incorporating prior knowledge into image registration. Neuroimage 1997; 6:344-352

25. Ashburner J, Friston KJ: Nonlinear spatial normalization using basis functions. Hum Brain Mapp 1999; 7:254-266 
26. Worsley KJ, Marrett S, Neelin P, Vandal AC, Friston KJ, Evans AC: A unified statistical approach for determining significant signals in images of cerebral activation. Hum Brain Mapp 1996; 4: 58-73

27. Friston KJ, Holmes A, Poline J-B, Price C, Frith CD: Detecting activations in PET and fMRI: levels of inference and power. Neuroimage 1995; 4:223-235

28. Pakkenberg B: Pronounced reduction of total neuron number in mediodorsal thalamic nucleus and nucleus accumbens in schizophrenics. Arch Gen Psychiatry 1990; 47:1023-1028

29. Popken GJ, Bunney WE Jr, Potkin SG, Jones EG: Subnucleus-specific loss of neurons in medial thalamus of schizophrenics. Proc Natl Acad Sci USA 2000; 97:9276-9280

30. Andreasen NC, Ehrhardt JC, Swayze VW II, Alliger RJ, Yuh WT, Cohen G, Ziebell S: Magnetic resonance imaging of the brain in schizophrenia: the pathophysiologic significance of structural abnormalities. Arch Gen Psychiatry 1990; 47:35-44

31. Buchsbaum MS, Someya T, Teng CY, Abel L, Chin S, Najafi A, Haier RJ, Wu J, Bunney WE Jr: PET and MRI of the thalamus in never-medicated patients with schizophrenia. Am J Psychiatry 1996; 153:191-199

32. Gur RE, Maany V, Mozley PD, Swanson C, Bilker W, Gur RC: Subcortical MRI volumes in neuroleptic-naive and treated patients with schizophrenia. Am J Psychiatry 1998; 155:1711-1717

33. Staal WG, Hulshoff Pol HE, Schnack H, van der Schot AC, Kahn RS: Partial volume decrease of the thalamus in relatives of patients with schizophrenia. Am J Psychiatry 1998; 155:17811783

34. Hazlett EA, Buchsbaum MS, Byne W, Wei T-C, Spiegel-Cohen J, Geneve C, Kinderlehrer R, Haznedar MM, Shihabuddin L, Siever LJ: Three-dimensional analysis with MRI and PET of the size, shape, and function of the thalamus in the schizophrenia spectrum. Am J Psychiatry 1999; 156:1190-1199

35. Portas CM, Goldstein JM, Shenton ME, Hokama HH, Wible CG, Fischer I, Kikinis R, Donnino R, Jolesz FA, McCarley RW: Volumetric evaluation of the thalamus in schizophrenic male patients using magnetic resonance imaging. Biol Psychiatry 1998; 43:649-659
36. Wolkin A, Rusinek H, Vaid G, Arena L, Lafargue T, Sanfilipo M, Loneragan C, Lautin A, Rotrosen J: Structural magnetic resonance image averaging in schizophrenia. Am J Psychiatry 1998; 155:1064-1073

37. Arciniegas D, Rojas DC, Teale P, Sheeder J, Sandberg E, Reite M: The thalamus and the schizophrenia phenotype: failure to replicate reduced volume. Biol Psychiatry 1999; 45:1329-1335

38. Silbersweig DA, Stern E, Frith C, Cahill C, Holmes A, Grootoonk $S$, Seaward J, McKenna P, Chua SE, Schnorr L, Jones T, Frackowiak RSJ: A functional neuroanatomy of hallucinations in schizophrenia. Nature 1995; 378:176-179

39. Andreasen NC, Swayze V, O'Leary DS, Nopoulos P, Cizadlo T, Harris G, Arndt S, Flaum M: Abnormalities in midline attentional circuitry in schizophrenia: evidence from magnetic resonance and positron emission tomography. Eur Neuropsychopharmacol Suppl 1995; 5:37-41

40. Rubia K, Russell T, Bullmore ET, Soni W, Brammer MJ, Simmons A, Taylor E, Andrew C, Giampietro V, Sharma T: An fMRI study of reduced left prefrontal activation in schizophrenia during normal inhibitory function. Schizophr Res 2001; 52:47-55

41. Tononi G, Edelman GM: Schizophrenia and the mechanisms of conscious integration. Brain Res Brain Res Rev 2000; 31:391400

42. Andreasen NC: The role of the thalamus in schizophrenia. Can J Psychiatry 1997; 42:27-33

43. Flashman LA, Flaum M, Gupta S, Andreasen NC: Soft signs and neuropsychological performance in schizophrenia. Am J Psychiatry 1996; 153:526-532

44. Weinberger DR: Schizophrenia and the frontal lobe. Trends Neurosci 1988; 11:367-370

45. Liddle PF, Morris DL: Schizophrenic syndromes and frontal lobe performance. Br J Psychiatry 1991; 158:340-345

46. Barch DM, Carter CS, Braver TS, Sabb FW, MacDonald A III, Noll DC, Cohen JD: Selective deficits in prefrontal cortex function in medication-naive patients with schizophrenia. Arch Gen Psychiatry 2001; 58:280-288

47. Johnstone EC, Frith CD, Lang FH, Owens DG: Determinants of the extremes of outcome in schizophrenia. Br J Psychiatry 1995; 167:604-609 